\title{
Need for additional professional psychosocial and spiritual support in patients with advanced diseases in the course of specialist palliative care - a longitudinal observational study
}

Anneke Ullrich ${ }^{1}$, Holger Schulz ${ }^{2}$, Sven Goldbach ${ }^{3}$, Wiebke Hollburg ${ }^{3}$, Annette Rommel ${ }^{4}$, Marten Müller ${ }^{5}$, Denise Kirsch ${ }^{6}$, Katrin Kopplin-Förtsch ${ }^{7}$, Julia Messerer ${ }^{1}$, Louise König ${ }^{1}$, Frank Schulz-Kindermann²,

Carsten Bokemeyer ${ }^{1}$ and Karin Oechsle ${ }^{1^{*}}$ (i)

\begin{abstract}
Background: We investigated the need for additional professional support and associated factors in patients (pts) at initiation and in the course of in- and outpatient specialist palliative care (I-SPC/O-SPC).

Methods: Pts entering an urban SPC network consecutively completed questionnaires on psychosocial/spiritual problems and support needs within $72 \mathrm{~h}$ (T0) as well as within the first 6 weeks (T1) of SPC. Hierarchical linear regression analysis was used to investigate the impact of sociodemographic / disease-related variables, psychological / physical burden, social support, and SPC setting on the extent of support needs.

Results: Four hundred twenty-five pts (70years, 48\% female, 91\% cancer, 67\% O-SPC) answered at T0, and 167 at T1. At T0, main problems related to transportation, usual activities, and dependency (83-89\%). At T1, most prevalent problems also related to transportation and usual activities and additionally to light housework (82-86\%). At T0, support needs were highest for transportation, light housework, and usual activities (35-41\%). Cross-sectional comparisons of SPC settings revealed higher problem scores in O-SPC compared to I-SPC at T0 ( $p=.039)$, but not at T1. Support need scores were higher in O-SPC at T0 $(p<.001)$, but lower at T1 $(p=.039)$. Longitudinal analyses showed a decrease of support need scores over time, independent from the SPC setting. At T0, higher distress ( $p=.047)$, anxiety/depression $(p<.001)$, physical symptom burden $(p<.001)$ and I-SPC $(p<.001)$ were associated with higher support need scores (at T1: only higher distress, $p=.037$ ).
\end{abstract}

Conclusion: Need for additional professional psychosocial/spiritual support was identified in up to $40 \%$ of pts. with higher need at the beginning of O-SPC than of I-SPC. During SPC, this need decreased in both settings, but got lower in O-SPC than in I-SPC over time. Support need scores were not only associated with psychological, but also physical burden.

\footnotetext{
*Correspondence: kaoechsl@uke.de

1 Palliative Care Unit, Department of Oncology, Hematology and BMT,

University Medical Center Eppendorf, Martinistrasse 52, 20246 Hamburg,

Germany

Full list of author information is available at the end of the article
}

(c) The Author(s) 2021. Open Access This article is licensed under a Creative Commons Attribution 4.0 International License, which permits use, sharing, adaptation, distribution and reproduction in any medium or format, as long as you give appropriate credit to the original author(s) and the source, provide a link to the Creative Commons licence, and indicate if changes were made. The images or other third party material in this article are included in the article's Creative Commons licence, unless indicated otherwise in a credit line to the material. If material is not included in the article's Creative Commons licence and your intended use is not permitted by statutory regulation or exceeds the permitted use, you will need to obtain permission directly from the copyright holder. To view a copy of this licence, visit http://creativecommons.org/licenses/by/4.0/. The Creative Commons Public Domain Dedication waiver (http://creativeco mmons.org/publicdomain/zero/1.0/) applies to the data made available in this article, unless otherwise stated in a credit line to the data. 
Keywords: Palliative care, Support needs, Specialist palliative care, Psychosocial needs, Spiritual needs

\section{Background}

Palliative care aims to address complex problems and needs of patients including physical, psycho-spiritual, and socio-cultural aspects [1]. For cancer patients, still representing the major patient group receiving palliative care in Western countries, professional support in coping with tasks, accepting the disease, generating strength, feeling trust, strengthening the sense of control and other psychosocial and spiritual needs is considered as part of standard patient care $[2,3]$. However, international experts complain that "the multiple and varying needs of patients are still not being met adequately as part of routine cancer care" [4]. Various studies underline this complaint, demonstrating high proportions of unmet needs (50-90\%) in patients with cancers across all stages and during the whole disease trajectory [5-8]. It has also been shown that non-cancer patients present with similar main needs compared to a matched cohort of cancer patients, although there were some differences in quality, but not quantity of physical symptom burden [9].

Clinical studies showed that timely inclusion of specialist palliative care (SPC) can not only improve quality of life or symptom burden, but is also associated with a better addressing of patients' needs, especially concerning information and care planning [10]. Psychosocial and spiritual interventions can successfully meet the complex psychosocial and spiritual needs of patients with advanced diseases [11-14].

SPC is offered in inpatient (I-SPC) and outpatient settings (O-SPC). Usually, the SPC setting is chosen according to patients' individual wishes and needs. However, there are various factors reducing the probability that an outpatient care setting can address the patients' needs adequately, e.g. patients living alone at home without any family caregivers [15], patients' age or multi-morbidity [16]. In Germany, I-SPC was established as a billable service in 2005, and O-SPC has become prescribable by law in 2007 [17]. In contrast to the multi-professional principles of SPC in general and to the setting of I-SPC, O-SPC only comprises bi-professional care by specialized physicians and nurses, because the services of other professions such as psychologists or therapists are not covered by health insurance $[7,18]$. This contrast becomes particularly manifest when patients are discharged to home care when the psychological and psycho-oncological care is interrupted $[7,19]$. In daily practice, voluntary hospice workers often provide home-based psychosocial and spiritual care, while inclusion of professional support is rare and heterogeneous. This might indicate a possible care deficit, especially because up to $50 \%$ of terminally ill patients in home settings suffer from mental disorders [20].

The urban area of Hamburg was the first region in Germany that had established a complete and comprehensive network of I-SPC and O-SPC. Therefore, Hamburg can be regarded as a prime example for multi-institutional SPC networks. In this setting it is promising to evaluate if such a comprehensive SPC network can adequately address the complex problems and needs of patients with advanced diseases and terminal illnesses.

The main aim of the present study was to explore problems related to psychosocial and spiritual problems of patients at initiation and during SPC and to identify their need for additional professional support in these domains. Secondary aims concerned possible differences between patients entering I-SPC versus O-SPC. Further, we investigated the impact of sociodemographic and disease-related variables, physical symptom burden, distress, anxiety/depression and SPC setting on the extent of patients' need for additional professional support.

\section{Methods}

This prospective, observational longitudinal multicenter study was carried out in Hamburg, Germany. In a 12 months' period between June 2017 and July 2018, patients were consecutively enrolled in six SPC services of an urban network, including three SPC home care services (O-SPC) and three SPC wards (I-SPC). Within $72 \mathrm{~h}$ after first admission, patients were recruited by trained staff of the services.

Inclusion criteria were being older than 18 years, suffering from an advanced, life-limiting illness (cancer and non-cancer), and entering in- or outpatient SPC for the first time. The participating centers cared mainly for patients with advanced cancer resulting in an expectable underrepresentation of non-cancer patients. However, these patients represent a typical cohort during SPC in Europe where up to $90 \%$ of SPC patients suffer from oncological diseases [21]. Previous studies also suggest that the problems and needs are similar between cancer and non-cancer patients [9, 22]. However, two studies comparing cancer and non-cancer patients, suggest that non-cancer patients present with lower functional status when first entering SPC [22, 23]. Exclusion criteria were cognitive or language problems hampering informed consent and/or answering questionnaires, acute physical or psychological crisis entailing the risk that study participation would significantly increase 
patients' burden, and patients' imminent death. Reasons for study exclusion or non-participation were systematically documented.

Self-report questionnaires were used for data collection, which were handed out personally by staff of the SPC services. Patients' assistance for answering questionnaires was allowed upon request. Baseline data (T0) were collected within $72 \mathrm{~h}$ after admission to gain information about the patients' situation at initiation of SPC. Follow-up measurements were scheduled as follows: As long as patients stayed in the same SPC service, questionnaires were administered every 4 weeks during ongoing SPC. Additionally, patients received a questionnaire before being transitioned to other SPC services or to non-SPC settings. The first questionnaire returned during the first 6 weeks of SPC served as follow-up (T1). Beyond this timeframe, further follow-ups were assessed according to the study protocol, but were not included in the current analysis due to limited sample sizes.

The ethical committee of the General Medical Council of Hamburg has approved the study protocol (PV5062). Written informed consent was obtained before study participation.

\section{Measurements}

\section{Outcome measure}

Problems and needs for additional professional support were measured by an adapted version of the Problems and Needs in Palliative Care Questionnaire - Short Version (PNPCQ-sv) [24, 25]. With permission of its authors, the questionnaire was professionally translated to German language, and comprehensibility was tested in a small convenience sample. In order to focus on psychosocial and spiritual issues, the adapted version omitted physical symptoms. The included 22 items comprised aspects of daily activities, autonomy, need of information, and social, psychological, spiritual and financial issues, which were considered as psychosocial and spiritual issues in the broadest sense.

Two independent sum scores were calculated: the "Extent of psychosocial and spiritual problems" score (short: problem score) and the "Extent of need for additional professional support" (short: support needs score). Each score ranges from 0 to 22 with higher values reflecting a higher number of problems or support needs. Scores for respondents with $\leq 4$ missing items were calculated by imputing the mean score for the missing items based on items completed by that individual. In case of $>4$ items $(20 \%)$, a score was not calculated for that individual. Respondents for which the problem score was not calculated were $9(2.1 \%)$ at T0, and $3(1.8 \%)$ at T1. Likewise, the support needs score was not calculated for 80 respondents $(18.8 \%)$ at $\mathrm{T} 0$ and $27(16.2 \%)$ at $\mathrm{T} 1$.

\section{Potential predictor variables}

The distress thermometer (DT) was used to assess psychological distress within the last week on an 11-point analogue scale. Clinically relevant distress with need of professional psychological support is indicated by a cut-off value of $\geq 5[26,27]$. The DT includes a problem list with 21 physical symptoms that can be classified to contribute to psychological distress or not. We used the sum score of distressing physical symptoms ("physical symptom count", 0-21) to estimate the range of patients' physical symptoms (see supplemental material 1).

The PHQ-4 including a two-item depression scale (PHQ-2), and a two-item anxiety scale (GAD-2) was used for measurement of depressive and anxiety symptoms [28].

In addition, patients reported on sociodemographic characteristics (i.e. age, marital status, educational level, living environment), as well as disease-related data (i.e. primary disease, previous nursing situation).

\section{Statistical analyses}

We performed descriptive analyses to examine study population characteristics and to describe patients' psychosocial and spiritual problems and their need for additional professional support.

Data of patients admitted to I-SCP vs. O-SPC at initiation of SPC (T0) and at follow-up during SPC (T1) were compared cross-sectional using chi-square-tests (Fisher's exact test if expected values in any cell were below 5) and two-sample t-tests (two-tailed).

The problem scores and support need score at T0 were compared with the respective scores at $\mathrm{T} 1 \mathrm{using}$ repeated measures ANOVA (RM-ANOVA) with setting (O-SPC vs. I-SPC) as a main factor. As measures of effect, we calculated partial eta-squared $\left(\mathrm{n}_{\mathrm{p}}{ }^{2} ;\right.$ small $=0.01$, medium $=0.06$, large $=0.14$ ).

Two hierarchical linear regression models (enter method) were used to investigate the impact of sociodemographic and disease-related variables, psychological and physical burden, and SPC setting on the extent of patients' need for additional support. Support needs scores at $\mathrm{T} 0$ and at $\mathrm{T} 1$ were defined as dependent variables, respectively. Sociodemographic variables were added in step 1 (Model 1), disease-related variables at step 2 (Model 2), proxy-variables for social support at step 3 (Model 3), physical burden at step 4 (Model 4), and variables reflecting psychological burden at step 5 (Model 
5). Categorical predictor variables were dichotomized. Examination of correlations among the predictor variables revealed no problems with multicollinearity. Missing data were handled using the list wise deletion method.

All significance tests were two-tailed using a significance level of $\alpha<.05$. Analyses were completed using SPSS software version 25.0 (IBM, 2017).

\section{Results}

Patient recruitment and characteristics

During recruitment, 1713 patients were admitted to the six participating services. Of these, 713 (42\%) were eligible for study inclusion, and 443 were willing to participate (61\%). Among 425 who returned the baseline questionnaires (T0), 285 were admitted to O-SPC (67\%) and 140 to I-SPC (33\%). At follow-up during SPC (T1), 167 patients




(39\%) answered a questionnaire. At this time point, $130(78 \%)$ were treated in O-SCP and 37 (22\%) in I-SPC (Fig. 1).

Overall, at initiation of SPC (T0) $52 \%$ of 425 patients were male (mean age 69.7 \pm 12.5 years) and 91\% suffered from cancer. Patients admitted to O-SPC were significantly younger $(p<.001)$ and had needed less intensive nursing prior to SPC $(p=.008)$ than in I-SPC (Table 1).

Table 1 Patient characteristics at baseline $(N=425)$

\begin{tabular}{|c|c|c|c|c|}
\hline & $\begin{array}{l}\text { Whole sample }(N=425) \\
\mathrm{n}(\%)\end{array}$ & $\begin{array}{l}\text { O-SPC }(N=285) \\
\mathrm{n}(\%)\end{array}$ & $\begin{array}{l}\text { I-SPC }(N=140) \\
n(\%)\end{array}$ & $p$ \\
\hline Age, M (SD) & $69.7(12.5)$ & $71.4(11.3)$ & $66.2(14.0)$ & $<.001^{\mathrm{a}}$ \\
\hline \multicolumn{5}{|l|}{ Age groups } \\
\hline$\leq 50$ & $28(6.6)$ & $15(5.3)$ & $13(9.3)$ & \multirow[t]{5}{*}{$.013^{b}$} \\
\hline $51-60$ & $65(15.3)$ & $35(12.3)$ & $30(21.4)$ & \\
\hline $61-70$ & $110(25.9)$ & $71(24.9)$ & $39(27.9)$ & \\
\hline $71-80$ & $136(32.0)$ & $99(34.7)$ & $37(26.4)$ & \\
\hline$\geq 81$ & $86(20.2)$ & $65(22.8)$ & $21(15.0)$ & \\
\hline \multicolumn{5}{|l|}{ Gender } \\
\hline Male & $220(51.9)$ & $146(51.4)$ & $74(52.9)$ & \multirow[t]{2}{*}{$.779^{b}$} \\
\hline Female & $205(48.1)$ & $138(48.6)$ & $66(47.1)$ & \\
\hline \multicolumn{5}{|l|}{ Primary disease } \\
\hline Gastrointestinal cancer & $104(24.5)$ & $63(22.1)$ & $41(29.3)$ & \multirow[t]{5}{*}{$.209^{b}$} \\
\hline Cancer of the respiratory system & 78 (18.4) & $60(21.1)$ & $18(12.9)$ & \\
\hline Urogenital and breast cancer & $136(32.0)$ & $90(31.6)$ & $46(32.9)$ & \\
\hline Other malignancies & $72(16.9)$ & $47(16.5)$ & $25(17.9)$ & \\
\hline Non-malignant diseases & $35(8.2)$ & $25(8.8)$ & $10(7.1)$ & \\
\hline \multicolumn{5}{|l|}{ Nationality } \\
\hline German & $395(95.9)$ & $260(94.5)$ & $135(98.5)$ & $.055^{b}$ \\
\hline \multicolumn{5}{|l|}{ Religious confession } \\
\hline Yes & $235(57.5)$ & $150(54.9)$ & $85(62.5)$ & $.14^{b} 5$ \\
\hline \multicolumn{5}{|l|}{ Family status } \\
\hline Single & $80(18.9)$ & $46(16.2)$ & $34(24.3)$ & \multirow[t]{3}{*}{$.105^{b}$} \\
\hline Married, life partnership & $211(49.8)$ & $143(50.4)$ & $68(48.6)$ & \\
\hline Divorced, widowed & $133(31.4)$ & $95(33.5)$ & $38(27.1)$ & \\
\hline \multicolumn{5}{|l|}{ Children } \\
\hline Yes & $302(71.4)$ & $205(72.2)$ & $97(69.8)$ & $.608^{b}$ \\
\hline \multicolumn{5}{|l|}{ Living environment } \\
\hline Living alone & $135(32.3)$ & $90(32.4)$ & $45(32.1)$ & \multirow[t]{3}{*}{$.427^{b}$} \\
\hline Living alone, but family nearby & $48(11.5)$ & $28(10.1)$ & $20(14.3)$ & \\
\hline Living with family & $235(56.2)$ & $160(57.6)$ & 75 (53.6) & \\
\hline \multicolumn{5}{|l|}{ Education } \\
\hline High school (12-13years) & $129(31.2)$ & $81(29.5)$ & $48(34.5)$ & \multirow[t]{3}{*}{$.566^{\mathrm{b}}$} \\
\hline Junior high school (10years) & $117(28.3)$ & $79(28.7)$ & $38(27.3)$ & \\
\hline Elementary school ( $\leq 9$ years) & $168(40.6)$ & $115(41.8)$ & $53(38.1)$ & \\
\hline \multicolumn{5}{|l|}{ Previous nursing situation } \\
\hline No nursing & $78(19.3)$ & $41(15.2)$ & $37(27.4)$ & \multirow[t]{4}{*}{$.008^{b}$} \\
\hline By relatives only & $151(37.3)$ & $99(36.7)$ & $52(38.5)$ & \\
\hline Nursing service only & $116(28.6)$ & 88 (32.6) & $28(20.7)$ & \\
\hline Nursing service and relatives & $60(14.8)$ & $42(15.6)$ & $18(13.3)$ & \\
\hline
\end{tabular}

Significant group differences are marked in bold

Abbreviations: O-SPC outpatient specialist palliative care, I-SPC inpatient specialist palliative care, $p t s$ patients

${ }^{\text {a }}$ T-test (two-tailed), ${ }^{b} \mathrm{Chi}^{2}$-Test 


\section{Cross-sectional analyses of problems at initiation and during SPC}

At initiation of SPC (T0), the five most prevalent problems were "transportation" (88.9\%), "difficulties in continuing the usual activities" (88.9\%), "being dependent of others" (82.6\%), "doing light housework" (82.1\%), and "body care, washing, dressing or toilet" (70.4\%). Problems in the psychological and spiritual domains were reported less often, but were still indicated by 44 to $69 \%$ (psychological issues) and 45 to $55 \%$ (spiritual issues) of patients. A significant difference between the O-SPC and I-SPC group was observed in six of 22 given problems. Except for one aspect, these problems were more frequent in $\mathrm{O}-\mathrm{SPC}$, resulting in a higher mean problem score in the O-SPC vs. I-SCP group (11.7 vs. 11.1, $p=.039)$.

During SPC (T1), the five most common problems were "transportation" (85.5\%), "difficulties in continuing the usual activities" (85.3\%), "doing light housework" (81.7\%), "difficulty coping with the unpredictability of the future" (67.3\%), and "body care, washing, dressing or toilet" (67.1\%). Again, psychological (39 to $67 \%$ ) and spiritual problems (37 to 58\%) were indicated less often. Problem scores did not differ significantly between patients receiving O-SPC vs. I-SPC at this point of time $(p=.278$.). However, patients receiving I-SPC more often reported problems regarding "transportation" $(p=.049)$ and "finding others not receptive to talking about the disease" ( $p=.003$, Table 2).

\section{Cross-sectional analyses of need for additional professional support at initiation and during SPC}

At T0, the five most common needs for additional professional support were "transportation" (40.5\%), "doing light housework" (38.4\%), "difficulties in continuing the usual activities" (35.2\%), "difficulty coping with the unpredictability of the future" (29.9\%), and "being dependent of others" (28.9\%). Need for additional professional support was indicated by 15.3 to $29.9 \%$ of patients concerning psychological problems, and 18.4 to $24.7 \%$ concerning spiritual problems. A significant difference between the O-SPC and I-SPC group was observed in nine of 22 given needs, including all spiritual aspects. These needs were consistently more prevalent in O-SPC compared to I-SPC. Additionally, the mean needs score showed to be significantly higher in patients receiving O-SPC (6.4 vs. $4.1 ; p<.001)$.

At T1, need for additional professional support had decreased in most aspects. Among 167 patients, the five most frequent needs for more support related to "transportation" (24.0\%), "doing light housework" (19.9\%), "being dependent of others" (19.7\%), "difficulties in continuing the usual activities" (19.6\%), and "difficulty coping with the unpredictability of the future" (13.2\%). Need for additional support was reported by 3.2 to $13.2 \%$ of patients for psychological problems, and by 9.0 to $11.8 \%$ for spiritual problems. During SPC (T1), the mean support need score was significantly lower in O-SPC compared to I-SPC (1.7 vs $3.2 ; p=.038)$. At the level of single needs, "difficulties to accept the disease" was experienced differently across SPC settings with patients in O-SPC reporting less need for support $(7.0 \%$ vs. $18.9 \%, p=.034$; Table 3).

\section{Longitudinal analyses of problems and need for additional professional support}

Comparing problem scores at T0 with T1, no significant effects were detected by RM-ANOVA. Analyzing the course of the support needs scores, significant improvement could be demonstrated over time (large time effect: $\left.p<.001, \mathrm{n}_{\mathrm{p}}{ }^{2}=.106\right)$, meaning that less needs were reported to be unmet. However, we found no significant effects of the setting (O-SPC/I-SPC) or interaction effects of time and setting (Table 4).

\section{Potential predictors for additional professional psychosocial or spiritual support needs at initiation and during SPC}

Predictors for the extent of support needs at both time points were identified by hierarchical linear regression analyses.

At T0, variables of step 1 to 3 (sociodemographic, disease-related, and proxy-variables for social support) only explained up to $5 \%$ of the variance in the support needs score, and SPC setting showed to be the single predictor. Physical burden, tested in step 4, explained an additional $25 \%$ of variance. Psychological factors, tested in step 5, explained an additional $10 \%$ of variance. Higher distress $(p=.047)$ and higher level of anxiety/depressive symptoms $(p<.001)$ were associated with the support needs score. Additionally, SPC setting $(p<.001)$ and physical burden $(p<.001)$ remained significantly associated in this final model.

At T1, variables tested in step 1 to 3 only explained up to $8 \%$ of the variance with primary disease being the only significant predictor. Physical burden, tested in step 4, explained an additional $4 \%$ of variance. Psychological factors, tested in step 5, explained an additional 7\% of variance when controlling the other factors. Higher distress ( $p=.037)$ was associated with the support needs score, and neither of the other factors remained significantly associated in the final model (Table 5). 
Table 2 Cross-sectional comparisons of patients' psychosocial and spiritual problems during O-SPC vs. I-SPC

\begin{tabular}{|c|c|c|c|c|c|c|c|c|}
\hline \multirow[b]{3}{*}{ Psychosocial and spiritual problems (PNPCQ-sv) } & \multicolumn{4}{|c|}{$\begin{array}{l}\text { At initiation of SPC (T0) } \\
(N=425)\end{array}$} & \multicolumn{4}{|l|}{$\begin{array}{l}\text { During SPC (T1) } \\
(N=167)\end{array}$} \\
\hline & $\begin{array}{l}\text { Whole sample } \\
(N=425)\end{array}$ & $\begin{array}{l}\text { O-SPC } \\
(N=285)\end{array}$ & $\begin{array}{l}\text { I-SPC } \\
(N=140)\end{array}$ & & $\begin{array}{l}\text { Whole sample } \\
(N=167)\end{array}$ & $\begin{array}{l}\text { O-SPC } \\
(N=125)\end{array}$ & $\begin{array}{l}\text { I-SPC } \\
(N=42)\end{array}$ & \\
\hline & n (\%) yes & n (\%) yes & n (\%) yes & $p^{a}$ & n (\%) yes & n (\%) yes & n (\%) yes & $p^{a}$ \\
\hline \multicolumn{9}{|l|}{ Daily activities } \\
\hline Body care, washing, dressing, or toilet & $299(70.4)$ & $204(72.9)$ & $95(67.9)$ & .286 & $112(67.1)$ & $84(67.2)$ & $28(66.7)$ & .949 \\
\hline Transportation & $378(88.9)$ & $261(92.9)$ & $117(84.2)$ & .005 & $141(85.5)$ & $109(76.2)$ & $32(88.6)$ & .049 \\
\hline Doing light housework & $349(82.1)$ & $244(87.1)$ & $105(76.1)$ & .004 & $134(81.7)$ & $102(82.9)$ & $32(78.0)$ & .484 \\
\hline \multicolumn{9}{|l|}{ Autonomy } \\
\hline Difficulties in continuing the usual activities & $378(88.9)$ & $256(91.1)$ & $122(88.4)$ & .382 & $139(85.3)$ & $105(85.4)$ & $34(85.0)$ & .955 \\
\hline Difficulty to give tasks out of hands & $232(54.6)$ & $154(55.0)$ & $78(57.4)$ & .650 & $88(53.3)$ & $62(50.0)$ & $26(63.4)$ & .136 \\
\hline Being dependent of others & $351(82.6)$ & $235(82.5)$ & $116(83.5)$ & .798 & $130(30.6)$ & $97(77.6)$ & $33(80.5)$ & .679 \\
\hline Experiencing loss of control over one's life & $272(64.0)$ & $180(64.1)$ & $92(68.1)$ & .412 & $93(56.0)$ & $65(52.4)$ & $28(66.7)$ & .108 \\
\hline \multicolumn{9}{|l|}{$\underline{\text { Social issues }}$} \\
\hline Problems in the relationship with life companion & $85(20.0)$ & $65(23.2)$ & $20(14.6)$ & .040 & $24(14.5)$ & $15(12.1)$ & $9(21.4)$ & .137 \\
\hline $\begin{array}{l}\text { Difficulties in talking about the disease with life } \\
\text { companion }\end{array}$ & $128(30.1)$ & $94(33.5)$ & $34(24.6)$ & .066 & $34(20.5)$ & $24(19.2)$ & $10(24.4)$ & .475 \\
\hline $\begin{array}{l}\text { Finding it difficult to talk about the disease, } \\
\text { because of not wanting to burden others }\end{array}$ & $225(52.9)$ & $156(55.9)$ & $69(50.7)$ & .320 & $67(40.1)$ & $49(39.2)$ & $18(42.9)$ & .676 \\
\hline $\begin{array}{l}\text { Finding others not receptive to talking about the } \\
\text { disease }\end{array}$ & $153(36.0)$ & $105(37.2)$ & $48(35.0)$ & .661 & $46(28.0)$ & $27(22.0)$ & $19(46.3)$ & .003 \\
\hline Difficulties in finding someone to talk to & $145(34.1)$ & $100(35.5)$ & $45(32.6)$ & .564 & $45(27.4)$ & $33(26.8)$ & $12(29.3)$ & .762 \\
\hline \multicolumn{9}{|l|}{$\underline{\text { Psychological issues }}$} \\
\hline Depressed mood & $188(44.3)$ & $131(46.5)$ & $57(41.3)$ & .319 & $64(38.6)$ & $48(38.7)$ & $16(38.1)$ & .944 \\
\hline $\begin{array}{l}\text { Difficulty coping with the unpredictability of the } \\
\text { future }\end{array}$ & $291(68.5)$ & $200(71.4)$ & $91(66.4)$ & .296 & $111(67.3)$ & $84(67.7)$ & $27(65.9)$ & .823 \\
\hline Difficulties to show emotions & $212(49.9)$ & $143(50.7)$ & $69(50.0)$ & .891 & $71(43.6)$ & 49 (39.8) & $22(55.0)$ & .093 \\
\hline \multicolumn{9}{|l|}{$\underline{\text { Spiritual issues }}$} \\
\hline Difficulties to be engaged usefully & $206(48.5)$ & $144(52.0)$ & $62(44.9)$ & .175 & $86(52.4)$ & $66(53.2)$ & $20(50.0)$ & .722 \\
\hline Difficulties to be of avail of others & $233(54.8)$ & $160(58.0)$ & $73(53.3)$ & .366 & $96(58.5)$ & $68(55.3)$ & $28(68.3)$ & .143 \\
\hline Difficulties concerning the meaning of death & $192(45.2)$ & $138(49.8)$ & $54(39.7)$ & .053 & $60(37.3)$ & $46(38.0)$ & $14(35.0)$ & .732 \\
\hline Difficulties to accept the disease & $233(54.8)$ & $168(59.2)$ & $65(47.1)$ & .019 & $83(50.9)$ & $61(49.6)$ & $22(55.0)$ & .522 \\
\hline \multicolumn{9}{|l|}{ Financial problems } \\
\hline Extra expenditures because of the disease & $125(29.4)$ & $85(30.5)$ & $40(29.2)$ & .791 & $40(27.4)$ & $29(23.8)$ & $11(27.5)$ & .635 \\
\hline Loss of income because of the disease & $71(16.7)$ & $39(14.1)$ & $32(23.7)$ & .015 & $28(17.5)$ & $20(16.7)$ & $8(20.0)$ & .631 \\
\hline \multicolumn{9}{|l|}{ Need of information } \\
\hline $\begin{array}{l}\text { Insufficient information, e.g. about the disease } \\
\text { and its treatment, aids and agencies that can pro- } \\
\text { vide help, alternative healing methods. }\end{array}$ & $140(32.9)$ & $105(37.9)$ & $35(25.4)$ & .011 & $38(23.5)$ & $27(22.1)$ & $11(27.5)$ & .487 \\
\hline $\begin{array}{l}\text { Score "Extent of psychosocial and spiritual prob- } \\
\text { lems" }(0-22) c, M(S D)\end{array}$ & $11.7(4.9)$ & $11.7(4.9)$ & $11.1(4.0)$ & $.039^{\mathrm{b}}$ & & $10.5(4.7)$ & $11.2(4.9)$ & $.278^{\mathrm{b}}$ \\
\hline
\end{tabular}

Significant group differences are marked in bold

Abbreviations: SPC specialist palliative care; pts., patients, O-SOC outpatient specialist palliative care, I-SPC inpatient specialist palliative care, $P N P C Q-s V$ Problems and Needs in Palliative Care Questionnaire - Short Version

${ }^{\text {a }}$ Chi $^{2}$-Test; ${ }^{\text {b }}$ T-test (two-tailed)

\section{Discussion}

This prospective longitudinal study evaluated psychosocial and spiritual problems of patients receiving I-SPC or O-SPC, their need for additional professional psychosocial and spiritual support and predictors for a higher number of support needs. 
Table 3 Cross-sectional comparisons of patients' need for additional professional psychosocial and spiritual support during O-SPC vs. I-SPC

\begin{tabular}{|c|c|c|c|c|c|c|c|c|}
\hline & \multicolumn{4}{|c|}{$\begin{array}{l}\text { At initiation of SPC (T0) } \\
(N=425)\end{array}$} & \multicolumn{4}{|l|}{$\begin{array}{l}\text { During SPC (T1) } \\
(N=167)\end{array}$} \\
\hline & $\begin{array}{l}\text { Whole sample } \\
(N=425)\end{array}$ & $\begin{array}{l}\text { O-SPC } \\
(N=285)\end{array}$ & $\begin{array}{l}\text { I-SPC } \\
(N=140)\end{array}$ & & $\begin{array}{l}\text { Whole sample } \\
(N=167)\end{array}$ & $\begin{array}{l}\text { O-SPC } \\
(N=125)\end{array}$ & $\begin{array}{l}\text { I-SPC } \\
(N=42)\end{array}$ & \\
\hline $\begin{array}{l}\text { Need for additional psychosocial and spiritual } \\
\text { support (PNPCQ-sv) }\end{array}$ & n (\%) yes & n (\%) yes & n (\%) yes & $p$ & n (\%) yes & n (\%) yes & n (\%) yes & p \\
\hline \multicolumn{9}{|l|}{ Daily activities: } \\
\hline Body care, washing, dressing, or toilet & $121(28.5)$ & $96(34.7)$ & $25(18.0)$ & $<.001^{\mathrm{a}}$ & $19(12.0)$ & $13(11.0)$ & $6(15.0)$ & $.503^{\mathrm{a}}$ \\
\hline Transportation & $172(40.5)$ & $121(45.0)$ & $51(38.6)$ & $.228^{\mathrm{a}}$ & $35(24.0)$ & $23(21.5)$ & $12(30.8)$ & $.245^{\mathrm{a}}$ \\
\hline Doing light housework & $163(38.4)$ & $120(45.1)$ & $43(32.8)$ & $.019^{\mathrm{a}}$ & 29 (19.9) & $20(18.0)$ & $9(25.7)$ & $.320^{\mathrm{a}}$ \\
\hline \multicolumn{9}{|l|}{ Autonomy: } \\
\hline Difficulties in continuing the usual activities & $150(35.2)$ & 99 (37.8) & $51(38.1)$ & $.958^{\mathrm{a}}$ & $28(19.6)$ & $17(16.2)$ & $11(28.9)$ & $.089^{\mathrm{a}}$ \\
\hline Difficulty to give tasks out of hands & $85(20.0)$ & $60(22.0)$ & $25(18.8)$ & $.460^{\mathrm{a}}$ & $12(8.0)$ & $6(5.5)$ & $6(15.0)$ & $.057^{\mathrm{a}}$ \\
\hline Being dependent of others & $123(28.9)$ & $85(31.3)$ & $38(28.6)$ & $.582^{\mathrm{a}}$ & $28(19.7)$ & $18(17.4)$ & $10(26.3)$ & $.232^{\mathrm{a}}$ \\
\hline Experiencing loss of control over one's life & $114(26.8)$ & $78(28.5)$ & $36(26.9)$ & $.735^{\mathrm{a}}$ & $14(9.7)$ & $8(7.6)$ & $6(15.4)$ & $.162^{\mathrm{a}}$ \\
\hline \multicolumn{9}{|l|}{ Social issues: } \\
\hline $\begin{array}{l}\text { Problems in the relationship with life compan- } \\
\text { ion }\end{array}$ & $38(8.9)$ & $29(10.4)$ & $9(6.6)$ & $.207^{\mathrm{a}}$ & $1(0.6)$ & $1(0.8)$ & $0(0)$ & $1.000^{b}$ \\
\hline $\begin{array}{l}\text { Difficulties in talking about the disease with life } \\
\text { companion }\end{array}$ & 59 (13.9) & $46(19.0)$ & $13(10.9)$ & $.051^{\mathrm{a}}$ & $2(1.3)$ & $1(0.8)$ & $1(2.4)$ & $.448^{b}$ \\
\hline $\begin{array}{l}\text { Finding it difficult to talk about the disease, } \\
\text { because of not wanting to burden others }\end{array}$ & $96(22.6)$ & $72(30.0)$ & $24(19.5)$ & $.032^{\mathrm{a}}$ & $7(4.6)$ & $3(2.7)$ & $4(9.8)$ & $.083^{b}$ \\
\hline $\begin{array}{l}\text { Finding others not receptive to talking about } \\
\text { the disease }\end{array}$ & $54(12.7)$ & $43(17.9)$ & $11(9.3)$ & $.033^{a}$ & $4(2.6)$ & $2(1.8)$ & $2(5.0)$ & $.280^{b}$ \\
\hline Difficulties in finding someone to talk to & $78(18.4)$ & $54(22.4)$ & $24(20.3)$ & $.655^{\mathrm{a}}$ & $3(1.9)$ & $1(0.9)$ & $2(4.9)$ & $.173^{b}$ \\
\hline \multicolumn{9}{|l|}{ Psychological issues: } \\
\hline Depressed mood & 75 (17.6) & $57(23.2)$ & $18(15.1)$ & $.075^{\mathrm{a}}$ & $5(3.2)$ & $4(3.5)$ & $1(2.4)$ & $1.000^{b}$ \\
\hline $\begin{array}{l}\text { Difficulty coping with the unpredictability of } \\
\text { the future }\end{array}$ & $127(29.9)$ & $88(35.8)$ & $39(30.5)$ & $.304^{\mathrm{a}}$ & $20(13.2)$ & $12(10.7)$ & $8(20.5)$ & .120 \\
\hline Difficulties to show emotions & $65(15.3)$ & $47(19.3)$ & $18(14.0)$ & $.199^{\mathrm{a}}$ & $7(4.5)$ & $4(3.4)$ & $3(7.3)$ & $.378^{b}$ \\
\hline \multicolumn{9}{|l|}{ Spiritual issues: } \\
\hline Difficulties to be engaged usefully & $78(18.4)$ & $59(24.6)$ & $19(15.6)$ & $.049^{a}$ & $13(9.0)$ & $10(9.3)$ & $3(8.1)$ & $1.000^{b}$ \\
\hline Difficulties to be of avail of others & $85(20.0)$ & $66(28.0)$ & $19(15.6)$ & $.009^{\mathrm{a}}$ & $17(11.8)$ & $10(9.3)$ & $7(19.4)$ & $.101^{\mathrm{a}}$ \\
\hline Difficulties concerning the meaning of death & $94(22.1)$ & $72(30.4)$ & $22(18.6)$ & $.018^{\mathrm{a}}$ & $16(10.3)$ & $10(8.7)$ & $6(15.0)$ & $.259^{\mathrm{a}}$ \\
\hline Difficulties to accept the disease & $105(24.7)$ & $88(36.5)$ & $17(14.4)$ & $<.001^{\mathrm{a}}$ & $15(9.9)$ & $8(7.0)$ & $7(18.9)$ & $.034^{\mathrm{a}}$ \\
\hline \multicolumn{9}{|l|}{ Financial problems: } \\
\hline Extra expenditures because of the disease & $66(15.5)$ & $48(21.0)$ & $18(14.8)$ & $.156^{\mathrm{a}}$ & $9(5.8)$ & $5(4.3)$ & $4(10.5)$ & $.225^{b}$ \\
\hline Loss of income because of the disease & $41(9.6)$ & $28(12.1)$ & $13(10.8)$ & $.732^{\mathrm{a}}$ & $9(5.8)$ & $6(5.1)$ & $3(7.9)$ & $.690^{\mathrm{b}}$ \\
\hline \multicolumn{9}{|l|}{ Need of information: } \\
\hline $\begin{array}{l}\text { Insufficient information, e.g. about the disease } \\
\text { and its treatment, aids and agencies that can } \\
\text { provide help, alternative healing methods. }\end{array}$ & $116(27.3)$ & $90(38.5)$ & $26(21.5)$ & $.001^{\mathrm{a}}$ & $15(9.6)$ & $9(7.6)$ & $6(15.8)$ & .133 \\
\hline $\begin{array}{l}\text { Score "Extent of need for additional professional } \\
\text { support" (0-22) M (SD) }\end{array}$ & & $6.4(6.5)$ & $4.2(4.1)$ & $<.001^{c}$ & & $1.7(2.9)$ & $3.2(4.0)$ & $.038^{c}$ \\
\hline
\end{tabular}

Significant group differences are marked in bold

Abbreviations: SPC specialist palliative care; pts., patients, O-SOC outpatient specialist palliative care, I-SPC inpatient specialist palliative care, PNPCQ-sV Problems and Needs in Palliative Care Questionnaire - Short Version

${ }^{a}$ Chi2-Test; ${ }^{b}$ Fisher's Exact Test; ${ }^{\mathrm{C}} \mathrm{T}$-test (two-tailed); d Higher scores reflect a greater number of needs for which additional professional psychosocial and spiritual support was indicated 
Table 4 Comparison of the total scores of psychosocial and spiritual problems as well as need for additional professional support assessed at initiation of specialist palliative care (T0) and at follow-up (T1) using repeated measures ANOVA

\begin{tabular}{|c|c|c|c|c|c|c|c|c|c|c|c|c|c|c|}
\hline & \multirow{2}{*}{$\begin{array}{l}\text { O-SPC } \\
\text { M (SD) }\end{array}$} & \multirow{2}{*}{$\begin{array}{l}\text { I-SPC } \\
M(S D)\end{array}$} & \multicolumn{4}{|c|}{ Main Effect Time } & \multicolumn{4}{|c|}{ Main Effect Setting } & \multicolumn{4}{|c|}{ Setting $\mathrm{x}$ Time Interaction } \\
\hline & & & $\overline{d f}$ & $F$ & $p$ & $\eta_{p}^{2}$ & $\overline{d f}$ & $F$ & p & $\eta_{p}^{2}$ & $\overline{\mathrm{df}}$ & $F$ & $p$ & $n_{p}^{2}$ \\
\hline \multicolumn{15}{|c|}{ Score "Extent of psychosocial and spiritual problems" (0-22) } \\
\hline At initiation of SPC (T0) & $11.2(4.9)$ & $10.8(3.8)$ & 1 & .797 & .373 & .005 & 1 & .000 & .996 & .000 & 1 & .700 & .404 & .004 \\
\hline During SPC (T1) & $10.5(4.7)$ & $10.8(4.7)$ & & & & & & & & & & & & \\
\hline \multicolumn{15}{|c|}{ Score "Extent of need for additional professional support" (0-22) } \\
\hline At admission (T0) & $4.8(5.8)$ & $3.6(3.5)$ & 1 & 13.158 & $<.001$ & .106 & 1 & .158 & .692 & .001 & 1 & 2.087 & .151 & .018 \\
\hline During SPC (T1) & $1.9(3.3)$ & $2.4(3.8)$ & & & & & & & & & & & & \\
\hline
\end{tabular}

Significant $p$-values are marked in bold

Abbreviations: SPC specialist palliative care, $M$ mean, SD standard deviation, d.f. degrees of freedom, $F$ F-statistic, $\eta_{p}^{2}$ partial eta square, $p$ probability of type I error

\section{Psychosocial and spiritual problems}

The most prevalent problems of patients at initiation of SPC were problems in the dimension of daily activities. During SPC, four of the five most frequent problems were still related to daily activities. However, with "difficulty coping with the unpredictability of the future" as fourth frequent problem, a psychological aspect gained on impact. In line, in a previous German study patients receiving O-SPC most commonly reported problems concerning daily activities (fatigue, getting around, eating, bathing/dressing) [29]. The impact of such impairments is also emphasized by a study reporting that problems in the area of functioning were most frequently complained by patients receiving SPC [30]. In our study, spiritual problems were less frequently identified than psychological problems, but still concerned about $40 \%$ of patients at both assessments. This matches with previous studies reporting an importance of spirituality / spiritual aspects during palliative care in about $30-40 \%$ of patients [31].

Comparing O-SPC and I-SPC, problems tended to be more frequent in the O-SPC group at initiation of SPC, which also reflected in significantly higher problem scores. Despite these differences, patients from both settings showed relevant problems requiring multi-professional care. In contrast, the setting did not influence problem scores at follow-up during SPC; however, prevalence of two single problems ("transportation", "finding others not receptive to talking about the disease") was significantly higher in the I-SPC group. In a retrospective study comparing O-SPC and I-SPC, O-SPC patients had worse function and higher need for care planning and family support [31, 32].

Longitudinal analyses of problem scores showed no significant effects of time and setting. This might not be surprising as the patients' advanced diseases progress over time, and SPC could only maintain stability of symptoms and problem burden.

\section{Need for additional professional psychosocial and spiritual support}

The need for additional support was lower than the extent of the corresponding problems at both assessments indicating that patients might not expect or want professional support for every problem they perceive, especially regarding psychological and spiritual problems. While some patients require deeper psychological and spiritual support (ranging from approximately 10 to $40 \%$ ), others might prefer to cope with such problems themselves. Additionally, some problems might be addressed by informal support, e.g. family caregivers, or patients might not be able to feel and express their need for additional professional support.

Reviewing the relative prevalence of needs reported in our study, need for additional support related to daily activities was most common both at initiation and during SPC: At initiation of SPC, the three most common needs for additional support concerned daily activities, followed by two psychological issues regarding the difficulty to cope with the unpredictability of the future and being dependent of others. During SPC, the need for additional support decreased in most aspects with the same needs representing the "top five". Literature on patients' support needs mainly relates on cancer patients [8, 30, 33-42]. These studies also demonstrate that daily living, practical support, information and emotional/psychological support consistently represent the most prevalent unmet support needs [8, 30, 33-42]. In line with the results from our study, a repeatedly mentioned psychological problem causing support need is the unpredictably of future $[8,38,41]$.Additional need for professional spiritual support was lower with about $20 \%$ at initiation of SPC and about $10 \%$ during follow-up indicating that such support is required by a subgroup of patients. However, studies strengthen the lack of spiritual support even during SPC in a still relevant number of patients [9]. 
Table 5 Summary of hierarchical regression analysis for variables predicting the extent of need for additional professional psychosocial and spiritual support when first entering SPC (T0) and during SPC (T1)

\begin{tabular}{|c|c|c|c|c|c|}
\hline Predictor variables $^{a}$ & $\begin{array}{l}\text { Model } 1 \\
\text { B }\end{array}$ & $\begin{array}{l}\text { Model } 2 \\
\text { B }\end{array}$ & $\begin{array}{l}\text { Model } 3 \\
\text { B }\end{array}$ & $\begin{array}{l}\text { Model } 4 \\
B\end{array}$ & $\begin{array}{l}\text { Model } 5 \\
\text { B }\end{array}$ \\
\hline \multicolumn{6}{|c|}{ Score "Need for additional professional support at initiation of SPC" $\left(T 0, N=314^{b}\right)$} \\
\hline Age & -.01 & -.03 & -.05 & -.02 & -.02 \\
\hline Gender (0, female; 1 , male) & .01 & .15 & .01 & .02 & -.03 \\
\hline Primary disease $(0$, non-cancer; 1 , cancer $)$ & & -.12 & -.11 & -.10 & -.04 \\
\hline SPC setting ( 0 , inpatient; 1 , outpatient) & & $.17^{* *}$ & $.17^{* *}$ & $.21^{* * *}$ & $.17^{* * *}$ \\
\hline Care site prior SPC (0, at home 1 ; nursing home/hospital) & & -.04 & -.04 & -.04 & -.03 \\
\hline Having children ( 0 , no; 1 , yes) & & & -.03 & -.01 & -.01 \\
\hline Living situation ( 0 , living alone; 1 , with relatives or relatives nearby) & & & -.08 & $-.12^{*}$ & -.09 \\
\hline Physical symptom count (0-21) & & & & $.51^{* * *}$ & $.33^{* * *}$ \\
\hline Distress (DT;0-10) & & & & & $.10^{*}$ \\
\hline Anxiety/depressive symptoms (PHQ-4;0-12) & & & & & $.33^{* * *}$ \\
\hline$R^{2}$ & .00 & .04 & .05 & .30 & .40 \\
\hline Adjusted $R^{2}$ & -.01 & .03 & .03 & .28 & .38 \\
\hline$F$ for change in $R^{2}$ & .04 & 4.4 & 1.4 & 109.73 & 26.02 \\
\hline \multicolumn{6}{|l|}{ Score "Need for additional professional support during $\operatorname{SPC}\left(T 1, N=129^{b}\right)$} \\
\hline Age & -.11 & -.13 & -.12 & -.14 & -.10 \\
\hline Gender (0, female; 1 , male) & .08 & .09 & .08 & .08 & .02 \\
\hline Primary disease $(0$, non-cancer; 1 , cancer $)$ & & $-.18^{*}$ & $-.19^{*}$ & $-.19^{*}$ & -.14 \\
\hline SPC setting ( 0 , inpatient; 1 , outpatient) & & -.16 & -.15 & -.12 & -.10 \\
\hline Care site prior SPC (0, at home 1; nursing home/hospital) & & -.08 & -.08 & -.07 & -.04 \\
\hline Having children (0, no; 1 , yes) & & & -.03 & -.01 & .03 \\
\hline Living situation ( 0 , living alone; 1 , with relatives or relatives nearby) & & & -.03 & -.07 & -.08 \\
\hline Physical symptom count (0-21) & & & & $.21^{*}$ & 1.0 \\
\hline Distress (DT; 0-10) & & & & & $2.0^{*}$ \\
\hline Anxiety/depressive symptoms (PHQ-4;0-12) & & & & & .19 \\
\hline$R^{2}$ & .02 & .08 & .08 & .12 & .19 \\
\hline Adjusted $R^{2}$ & .00 & .04 & .03 & .06 & .13 \\
\hline$F$ for change in $R^{2}$ & 1.04 & 2.7 & .18 & 5.67 & 5.30 \\
\hline
\end{tabular}

Hierarchical linear regression analysis (enter method). Step 1: demographic variables (age, sex), step 2: care-related variables (primary disease, SPC setting, care site prior SPC); step 3: proxy-variables for social support (children, living situation), step 4: Physical burden (physical symptom count), step 5: variables reflecting psychological burden (distress, anxiety/depressive symptoms)

Abbreviations: B Standardized regression coefficients, SPC specialist palliative care, DT Distress Thermometer, PHQ-4 Patient Health Questionnaire 4-item version

a All potential predictor variables were measured at onset of specialist palliative care (T0), ${ }^{\text {b }}$ Reduced sample size due to missing values (analyzed by listwise deletion)

${ }^{*} p<.05$

** $p<.01$

$* * * 0<.001$

These findings are both understandable and consistent with Maslow's hierarchy of needs theory [43]. Maslow's hierarchy of needs divides human needs in five categories from low to high (like a pyramid), starting with basic physiological demands. The theory proposes that if needs of a certain level are satisfied, the next higher need emerges and the pursuit of a higher level of needs becomes the driving force for behavior. In our study, the highest needs for additional professional support related to the more basic needs, like daily activities and transportation, which may have to be met for patients to feel safe enough to attend to psychological and spiritual needs. However, our findings also indicated that higher needs may already be important although lower-level may have not been met. Despite the usefulness of this theory for assessing patients' needs in palliative care, the criticism that Maslow's ranking of needs might be overly simplistic has to be kept in mind [44].

Comparing SPC settings, patients scored significantly higher additional support need when entering O-SPC. Interestingly, during SPC, the need for additional 
psychosocial and spiritual support was higher in I-SPC. However, higher support needs during inpatient compared to outpatient care in cancer patients have been demonstrated [33].

Longitudinal analyses of patients' need for additional support showed a significant improvement over time, but without any difference between the two SPC settings. This result indicates that the two different SPC settings satisfy the needs of the referred patient cohorts, which strengthens the results of a previous study demonstrating that SPC could meet the needs of their target group [39].

\section{Factors associated with additional professional support needs}

At initiation of SPC, higher support need scores were associated with higher physical symptom burden, higher distress, higher levels of anxiety/depression and I-SPC setting. In contrast, during SPC, higher distress revealed to be the only predictor of support needs. Previous studies have also reported significant effects of distress and problem or symptom burden on patients' support needs [29]. In our study, sociodemographic or disease-related factors were not identified to be predictive, which is in line with previous studies that could not find any or only partial associations between sociodemographic or medi$\mathrm{cal} /$ disease-related factors in patients with advanced diseases $[29,38,40]$. Only one study including older cancer patients observed that non-white, divorced or never married patients had higher unmet social support needs [39].

\section{Strengths and limitations}

This study has some strengths, e.g. the prospective longitudinal design, consecutive patient recruitment within an established SPC network, and systematic documentation of non-response. In addition, our study specifically evaluates the need for professional support in patients receiving SPC. Previous study mainly analyzed "unmet needs" which does not clarify if the patients expect professional or non-professional support, e.g. from family caregivers.

However, there are some limitations that have to be noticed. Our SPC network is located in an urban region and it remains unclear if these results could be transferred to patients in more rural areas.

We included aspects of daily living as psychosocial aspects when using the PNPC-sv, while some other questionnaires define them as a separate or physical category. However, the PNPC-sv is one of the two most commonly used questionnaire in needs assessment at least in cancer patients [36]. Overall, the different questionnaires used for needs assessment hamper comparability of data in general $[35,36]$.

In conclusion, a relevant number of problems, mainly concerning limited daily activities, should be considered in patients entering SPC. Psychological and spiritual problems could be expected more frequently in patients entering O-SPC, but this difference will be balanced during SPC, indicating that SPC services can meet professional care for basic needs, but also for higher-level needs, like psychological and spiritual needs. However, healthcare professionals should respect that patients do not expect or want professional support for all of their problems. In daily routine care, assessments should be used that allow to distinguish between problems and (unmet) needs, which are two different concepts. Patients requests for additional professional support mainly concern aspects of daily living, dependency and coping with the unpredictability of the future. Spiritual problems and need for additional professional support are less frequent than psychological. Patients' need for additional support decreases during SPC, but does not show any difference between the two SPC settings. Patients' support needs are associated with psychological distress and physical symptom burden, but not sociodemographic or disease-related factors.

\section{Supplementary Information}

The online version contains supplementary material available at https://doi. org/10.1186/s12904-021-00880-6.

Additional file 1: Supplemental Material 1. Patients' distressing physical problems during O-SPC vs. I-SPC (cross-sectional).

\section{Acknowledgements}

The support of all patients who participated in the present study was highly appreciated. We thank all staff members of the participating palliative care services for their dedicated and valuable work. Without them, conduct of this study would not have been possible. The authors would like to thank Maren Wögens and Lisa K. Hackspiel for their research assistance.

\section{Authors' contributions}

Conception and design: Karin Oechsle, Holger Schulz, Frank SchulzKindermann. Provision of study materials or patients: Sven Goldbach, Wiebke Hollburg, Annette Rommel, Marten Müller, Denise Kirsch, Kathrin Kopplin-Foertsch, Carsten Bokemeyer. Collection and assembly of data: Sven Goldbach, Wiebke Hollburg, Annette Rommel, Marten Müller, Denise Kirsch, Kathrin Kopplin-Foertsch, Anneke Ullrich, Julia Messerer, Louise König. Data analysis and interpretation: Anneke Ullrich, Holger Schulz, Julia Messerer, Louise König. Manuscript writing: Anneke Ullrich, Karin Oechsle, Holger Schulz. Final approval of manuscript: Anneke Ullrich, Holger Schulz, Sven Goldbach, Wiebke Hollburg, Annette Rommel, Marten Müller, Denise Kirsch, Kathrin Kopplin-Foertsch, Julia Messerer, Louise König, Frank Schulz-Kindermann, Carsten Bokemeyer, Karin Oechsle

\section{Funding}

Open Access funding enabled and organized by Projekt DEAL. This work was funded by the German Cancer Aid ("Deutsche Krebshilfe e.V.", grant number: 70112144).

The funders had no role in study design, data collection and analysis, decision to publish, or preparation of the manuscript.

Availability of data and materials

All authors have full control over the primary data. The data are analyzed in this study are housed at the Palliative Care Unit, Department of Oncology, 
Hematology and BMT, University Medical Center Hamburg-Eppendorf, Martinistrasse 52, 20246 Hamburg, Germany, Prof. Dr. Karin Oechsle, corresponding author. As per the ethical committee approval, this dataset is subject to ethical restrictions, and informed written consent of study participants does not include publication of raw data. All relevant data for the conclusions are presented in the manuscript.

\section{Declarations}

\section{Ethics approval and consent to participate}

The study has been performed according to the declaration of Helsinki. Ethical committee approval was granted by the General Medical Council of Hamburg, Germany (PV5062).

All study participants provided written informed consent for study participation, data analysis and publication.

\section{Consent for publication}

This manuscript contains no individual person's data in any form.

\section{Competing interests}

Authors declare no competing interest.

\section{Author details}

${ }^{1}$ Palliative Care Unit, Department of Oncology, Hematology and BMT, University Medical Center Eppendorf, Martinistrasse 52, 20246 Hamburg, Germany. ${ }^{2}$ Department of Medical Psychology, University Medical Center Eppendorf, Hamburg, Germany. ${ }^{3}$ Specialist Outpatient Palliative Care Team "PalliativPartner Hamburg GbR", Hamburg, Germany. ${ }^{4}$ Specialist Outpatient Palliative Care Team "Das Palliativteam", Hamburg, Germany. ${ }^{5}$ Palliative Care Ward, Asklepios Hospital Rissen, Hamburg, Germany. ${ }^{6}$ Specialist Outpatient Palliative Care Team "PCT Hamburg-West", Hamburg, Germany. ${ }^{7}$ Palliative Care Ward, Agaplesion Diakonie-Hospital, Hamburg, Germany.

Received: 6 May 2021 Accepted: 9 November 2021

Published online: 25 November 2021

\section{References}

1. Hodiamont F, Jünger S, Leidl R, Maier BO, Schildmann E, Bausewein C. Understanding complexity-the palliative care situation as a complex adaptive system. BMC Health Serv Res. 2019;19(1):157.

2. Hong J, Song Y, Liu J, Wang W, Wang W. Perception and fulfillment of cancer patients' nursing professional social support needs: from the health care personnel point of view. Support Care Cancer. 2014;22(4):1049-58.

3. Rohrmoser A, Preisler M, Bär K, Letsch A, Goerling U. Early integration of palliative/supportive cancer care-healthcare professionals' perspectives on the support needs of cancer patients and their caregivers across the cancer treatment trajectory. Support Care Cancer. 2017;25(5):1621-7.

4. Jordan K, Aapro M, Kaasa S, Ripamonti C, Scotté F, Strasser F, et al. European Society for Medical Oncology (ESMO) position paper on supportive and palliative care. Ann Oncol. 2018;29(1):36-43.

5. Chung J, Kulkarni GS, Morash R, Matthew A, Papadakos J, Breau RH, et al. Assessment of quality of life, information, and supportive care needs in patients with muscle and non-muscle invasive bladder cancer across the illness trajectory. Support Care Cancer. 2019;27(10):3877-85.

6. Kuon J, Vogt J, Mehnert A, Alt-Epping B, van Oorschot B, Sistermanns J, et al. Symptoms and needs of patients with advanced lung cancer: early prevalence assessment. Oncol Res Treat. 2019;42(12):650-9.

7. Alt-Epping B, Seidel W, Vogt J, Mehnert A, Thomas M, van Oorschot $B$, et al. Symptoms and needs of head and neck cancer patients at diagnosis of incurability-prevalences, clinical implications, and feasibility of a prospective longitudinal multicenter cohort study. Oncol Res Treat. 2016;39(4):186-91.

8. Boyes AW, Clinton-McHarg T, Waller AE, Steele A, D'Este CA, Sanson-Fisher RW. Prevalence and correlates of the unmet supportive care needs of individuals diagnosed with a haematological malignancy. Acta Oncol. 2015;54(4):507-14.

9. Bandeali S, des Ordons AR, Sinnarajah A. Comparing the physical, psychological, social, and spiritual needs of patients with non-cancer and cancer diagnoses in a tertiary palliative care setting. Palliat Support Care. 2019;18(5):513-8.

10. Walling AM, Tisnado D, Ettner SL, Asch SM, Dy SM, Pantoja P, et al. Palliative care specialist consultation is associated with supportive care quality in advanced cancer. J Pain Symptom Manag. 2016;52(4):507-14.

11. Mesquita AC, Chaves ÉCL, GAMd B. Spiritual needs of patients with cancer in palliative care: an integrative review. Curr Opin Support Palliat Care. 2017;11(4):334-40.

12. Mateo-Ortega D, Gómez-Batiste X, Maté J, Beas E, Ela S, Lasmarias $C$, et al. Effectiveness of psychosocial interventions in complex palliative care patients: a quasi-experimental, prospective, multicenter study. J Palliat Med. 2018;21(6):802-8.

13. Teo I, Krishnan A, Lee GL. Psychosocial interventions for advanced cancer patients: a systematic review. Psycho-Oncol. 2019;28(7):1394-407.

14. Rego F, Gonçalves F, Moutinho S, Castro L, Nunes R. The influence of spirituality on decision-making in palliative care outpatients: a crosssectional study. BMC Palliat Care. 2020;19(1):1-14.

15. Aoun $S M$, Breen $L J$, Howting D. The support needs of terminally ill people living alone at home: a narrative review. Health Psychol Behav Med. 2014;2(1):951-69.

16. Reinke LF, Vig EK, Tartaglione EV, Rise P, Au DH. Symptom burden and palliative care needs among high-risk veterans with multimorbidity. J Pain Symptom Manag. 2019;57(5):880-9.

17. Gemeinsamer Bundesausschuss: Spezialisierte ambulante Palliativversorgung. Available at https://www.g-ba.de/themen/veranlasste-leist ungen/palliativversorgung/ (Last accessed: 15 Oct 2021).

18. Jansky M, Lindena G, Nauck F. Stand der spezialisierten ambulanten Palliativversorgung (SAPV) in Deutschland-Verträge und Erfahrungen. Z Palliativmedizin. 2011;12(04):164-74.

19. Régincos P, Nau H, Hönemann E-M. Spannungsfeld stationäre-nachstationäre Versorgung in Palliative Care. Zeitschrift für Palliativmedizin. 2020;21(01):21-6.

20. Götze H, Brähler E, Gansera L, Polze N, Köhler N. Psychological distress and quality of life of palliative cancer patients and their caring relatives during home care. Support Care Cancer. 2014;22(10):2775-82.

21. Hess S, Stiel S, Hofmann S, Klein C, Lindena G, Ostgathe C. Trends in specialized palliative care for non-cancer patients in Germany--data from the national hospice and palliative care evaluation (HOPE). Eur $\rfloor$ Intern Med. 2014;25(2):187-92.

22. Bostwick D, Wolf S, Samsa G, Bull J, Taylor DH Jr, Johnson KS, et al. Comparing the palliative care needs of those with cancer to those with common non-cancer serious illness. J Pain Symptom Manag. 2017;53(6):1079-1084.e1071.

23. Scaccabarozzi G, Amodio E, Riva L, Corli O, Maltoni M, Di Silvestre G, et al. Clinical care conditions and needs of palliative care patients from five Italian regions: preliminary data of the DEMETRA project. Healthcare (Basel). 2020;8(3):221.

24. Osse BH, Vernooij MJ, Schadé E, Grol RP. Towards a new clinical tool for needs assessment in the palliative care of cancer patients: the PNPC instrument. J Pain Symptom Manag. 2004;28(4):329-41.

25. Osse BH, Vernooij-Dassen MJ, Schadé E, Grol RP. A practical instrument to explore patients' needs in palliative care: the problems and needs in palliative care questionnaire-short version. Palliat Med. 2007;21(5):391-9.

26. Roth AJ, Kornblith AB, Batel-Copel L, Peabody E, Scher HI, Holland JC. Rapid screening for psychologic distress in men with prostate carcinoma: a pilot study. Cancer. 1998:82(10):1904-8.

27. Mehnert A, Müller D, Lehmann C, Koch U. Die deutsche version des NCCN distress-thermometers: empirische Prüfung eines screeninginstruments zur erfassung psychosozialer belastung bei krebspatienten. Z Psychiatr Psychol Psychother. 2006;54(3):213-23.

28. Kroenke K, Spitzer RL, Williams JB, Löwe B. An ultra-brief screening scale for anxiety and depression: the PHQ-4. Psychosomatics. 2009;50(6):613-21.

29. Küttner S, Wüller J, Pastrana T. How much psychological distress is experienced at home by patients with palliative care needs in Germany? A cross-sectional study using the distress thermometer. Palliat Support Care. 2017;15(2):205

30. Funk-Lawler R, Mundey KR. Understanding distress among patients with cancer receiving specialized, supportive care services. Am J Hosp Palliat Care. 2020;37(10):830-6. 
31. O'Callaghan CC, Georgousopoulou E, Seah D, Clayton JM, Kissane D, Michael N. Spirituality and religiosity in a palliative medicine population: mixed-methods study. BMJ Support Palliat Care. 2020:bmjspcare-2020-002261. https://doi.org/10.1136/bmjspcare-2020-002261. Online ahead of print.

32. Smith GM, Calton BA, Rabow MW, Marks AK, Bischoff KE, Pantilat SZ, et al. Comparing the palliative care needs of patients seen by specialty palliative care teams at home versus in clinic. J Pain Symptom Manage. 2021;62(1):28-38

33. Chua GP, Pang GSY, Yee ACP, Neo PSH, Zhou S, Lim C, et al. Supporting the patients with advanced cancer and their family caregivers: what are their palliative care needs? BMC Cancer. 2020;20(1):1-15.

34. Williams GR, Pisu M, Rocque GB, Williams CP, Taylor RA, Kvale EA, et al. Unmet social support needs among older adults with cancer. Cancer. 2019;125(3):473-81.

35. Moghaddam N, Coxon H, Nabarro S, Hardy B, Cox K. Unmet care needs in people living with advanced cancer: a systematic review. Support Care Cancer. 2016;24(8):3609-22.

36. Wang T, Molassiotis A, Chung BPM, Tan J-Y. Unmet care needs of advanced cancer patients and their informal caregivers: a systematic review. BMC Palliat Care. 2018;17(1):96.

37. Rha SY, Lee HJ, Lee J. Unmet needs in the physical and daily living domain mediates the influence of symptom experience on the quality of life of gastric cancer patients. Support Care Cancer. 2020;28(3):1419-31.

38. Janda M, Steginga S, Dunn J, Langbecker D, Walker D, Eakin E. Unmet supportive care needs and interest in services among patients with a brain tumour and their carers. Patient Educ Couns. 2008;71(2):251-8.
39. Seekatz B, Lukasczik M, Löhr M, Ehrmann K, Schuler M, Keßler AF, et al. Screening for symptom burden and supportive needs of patients with glioblastoma and brain metastases and their caregivers in relation to their use of specialized palliative care. Support Care Cancer. 2017;25(9):2761-70.

40. Weißflog G, Hönig K, Gündel H, Lang D, Niederwieser D, Döhner H, et al. Associations between dyadic coping and supportive care needs: findings from a study with hematologic cancer patients and their partners. Support Care Cancer. 2017;25(5):1445-54.

41. Beesley VL, Price MA, Webb PM, O'Rourke P, Marquart L, Group AOCS, et al. Changes in supportive care needs after first-line treatment for ovarian cancer: identifying care priorities and risk factors for future unmet needs. Psycho-Oncol. 2013;22(7):1565-71.

42. Stegmann ME, Geerse OP, Tange D, Richel C, Brom L, Engelen V, et al. Experiences and needs of patients with incurable cancer regarding advance care planning: results from a national cross-sectional survey. Support Care Cancer. 2020;28(9):4211-7.

43. Maslow AH. A theory of human motivation. Psychol Rev. 1943;50(4):370-96.

44. Higginson IJ, Hart S, Koffman J, Selman L, Harding R. Needs assessments in palliative care: an appraisal of definitions and approaches used. J Pain Symptom Manag. 2007;33(5):500-5.

\section{Publisher's Note}

Springer Nature remains neutral with regard to jurisdictional claims in published maps and institutional affiliations.
Ready to submit your research? Choose BMC and benefit from:

- fast, convenient online submission

- thorough peer review by experienced researchers in your field

- rapid publication on acceptance

- support for research data, including large and complex data types

- gold Open Access which fosters wider collaboration and increased citations

- maximum visibility for your research: over $100 \mathrm{M}$ website views per year

At BMC, research is always in progress.

Learn more biomedcentral.com/submissions 